\title{
Generation of a Historical Weapon Ge and Its Impacts on Huaxia Culture
}

\author{
Zhuo $\mathrm{Lu}^{1}$ \\ ${ }^{1}$ Heilongjiang University, 150080 Harbin, Heilongjiang, P.R. China \\ Correspondent: Zhuo Lu, Heilongjiang University, 150080 Harbin, Heilongjiang, P.R. China. E-mail: \\ wklm@xs4all.nl
}

Received: November 13, 2017

Accepted: December 21, 2016

Online Published: January 4, 2018

doi:10.5539/ach.v10n1p57

URL: http://dx.doi.org/10.5539/ach.v10n1p57

\begin{abstract}
The history of Huaxia (Chinese: 華夏, a historical concept representing the Chinese nation and civi-lization) is full of wars. Various weapons were developed that are suitable for ground combat with horse-drawn vehicles. The weapon Ge (Chinese: 戈) was already used before 221 BC (before the Qin Dynasty, ca. 221-206 BC), and disappeared in around $25 \mathrm{AD}$ (at the end of Western Han Dynasty). In most other regions in the world, this type of weapon has hardly been used. The weapon axe was used in the ancient wars (in the same period) outside Ancient China (also called the Middle King-dom), such as in Mesopotamia (the area of the Tigris-Euphrates river system). However, the weapon axe is different from Ge, although there seem some similarities. This article provides an in-depth study and analysis of the reasons for the historic use of this unique weapon $\mathrm{Ge}$, of its development in Ancient China, and of its influence on (military and civil) culture.
\end{abstract}

Keywords: Ge (戈), weapon history, geography, climate, archaeology, culture, Chinese characters (漢字)

\section{Introduction}

Yan Huang (Chinese: 炎黃), which was more than 4000 years ago an ethnic group in Ancient China inhabiting the Yellow River basin area. It fought a number of wars in the area of the historic "Middle Kingdom", from which Huaxia (Hua-hsia; 華夏) developed. (Shi \& Hu (Eds.), 1996)

Various combat weapons were developed, e.g. the sword, polearm weapons, (cross) bow and arrow, spear, pike, battle axe, single-edged blade (such as the European glaive, the Japaniese naginata, and the Russian sovnya), and also Ge. Except Ge, all the other weapons are very similar, in terms of shape, function and operation, to weapons found in other regions in the world (Zhong, 1999). Ge belongs to the polearm (or pole weapon) category. It is designed for warfare with extended reach of over $3 \mathrm{~m}$ (Yang, 1977). Its weight is approximately $3 \mathrm{~kg}(\mathrm{Lu}, 1993)$.

The main components of Ge are: (1) sickle-shaped (or dagger-shaped) Hu; (2) front; (3) upper blade; (4) lower blade. These four components together are called Part Yuan (Chinese: 援). The backside of the weapon is called Part Nei (Chinese: 内), which is used for fixing the head in a bar to get balance with Part Yuan (see Figure 1).

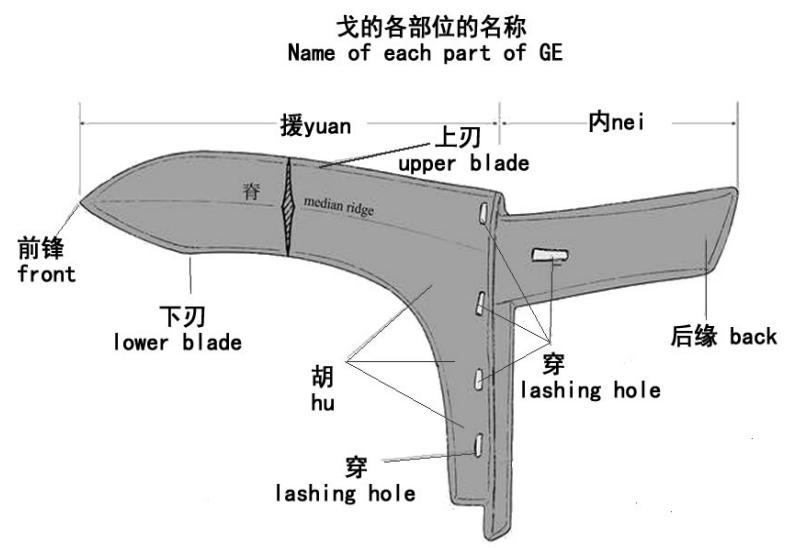

Figure 1. Illustration of the components of combat weapon Ge 
It has been suggested that Ge is more or less like battle axe, as both have the shape of a long beak of a bird, and that it is similar to other blade weapons with cutting capabilities, which were found in other areas outside Ancient China, such as in Mesopotamia, Germany and Spain (See Figure 2). And that therefore the historical weapon Ge was not unique (Zhou, 2006).

The author disagrees with this view. The most, and very essential difference between Ge and battle axe is that besides cutting capabilities, the additional function of Ge is to use its lower blade and a sickle-shaped $\mathrm{Hu}$ (see Figure 1 (left)) to attack the enemy. The sickle-shaped $\mathrm{Hu}$ is especially de-signed for lopping and cutting off. The power of the function also seems a lasso-like slinging and pulling. In summary, Ge has integrated functionality of lopping, shaping, splitting, slinging, hitting, pulling, cutting and cleaving. These characteristics make Ge unique weapon. Battle axes and other combat weapons found in areas outside Ancient China do not have the same integrated functionali-ty. In addition, the use of these various other combat weapons was different from the use of Ge. It should be noted that Ge was used in the period that horse-drawn combat vehicles were used. The vehicles were a kind of chariots using horses to provide rapid motive power, deployed in military as of transport as well as mobile platform for archery-based combat. Therefore, Ge is not the same as other long-ranged weapons (able to harm targets at distances greater than arm-length) or a melee weapon (intended for use in hand-to-hand combat). Section 3 will provide more details about the vehicles and the use of Ge.
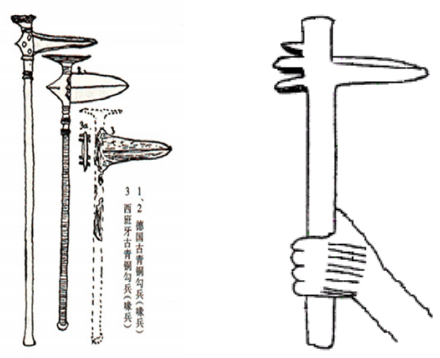

Figure 2. Illustrations of various battle axes found in other areas outside Ancient China (Left: Similar combat weapon found in Germany and Spain; Right: Battle axe found in Mesopotamia) (De Morgan, 1921)

According to the archaeologist J. Li (1932), Ge is a unique combat weapon invented in Ancient China. Based on research of the Ruins of Yin (Chinese: 殷墟, which is near current Anyang, Henan province, People's Republic of China), Li concluded that among the five weapons made in the Shang Dynasty (c. 1600-1046 BC), Ge was the only one that has never been found in any other areas of the world. The other four weapons were also created in other regions, such as ancient Europe, Egypt and Siberia (Li, 1932). Ge was only used in the period from roughly $221 \mathrm{BC}$ to $25 \mathrm{AD}$ (end of West-ern Han Dynasty), in Ancient China, and in some nearby areas influenced by Chinese culture, for instance Korea and Japan (Zhong, 1999).

Although the weapon Ge went out of use at the end of the Western Han Dynasty, its impact on Chinese culture is essential. Many Chinese characters (Chinese: 漢字) related to war or military, use "戈" Ge as radical, i.e. as structural component. Furthermore, Ge is used in traditional idiomatic ex-pressions (Chengyu, usually composed of four characters), essays and poems. In addition to becom-ing an important symbol, "Gan Ge" (Chinese: 干戈) is an alternative term for war in Chinese. Note that "Gan" means shield (Chinese: 盾牌).

This combat weapon was very widely used in Ancient China in a certain period. However, no con-vincing evidence was found of the use of Ge in any other area in the world. To the knowledge of the author, until now no adequate in-depth study was made of the peculiar position of $\mathrm{Ge}$, of the rea-sons of the development of this unique combat weapon, and of its impacts on culture. The research questions of this paper are:

1) How did the weapon Ge is develop?

2) Why it is uniquely applied in China in a certain period, especially during the Shang and Zhou dynasties?

3) What is the impact of Ge on ancient Chinese warfare and culture?

The paper is structured as follows: The next section investigates the background and development of Ge based on archaeological findings. Furthermore, it explores the reasons for and the factors influ-encing its development, as well as the reasons for using it only in a specific period (before $25 \mathrm{AD}$ ), and only in a certain area of Ancient China, based on in-depth studies of historical and geographical data. It also analyses the various impacts of $\mathrm{Ge}$ on 
associated military weapons and Chinese culture, and the reasons for these impacts. Moreover, it further discusses weapon development related to $\mathrm{Ge}$, such as relation to different historical periods, change of material, and relation to associated weap-ons. Finally, conclusions are drawn.

\section{Investigation of the Generation and Development of Ge in Ancient China}

Ge was found by archaeologists in various areas in the current P.R. China (see Figure 3). The ar-chaeological findings show that the weapon Ge was invented with different shapes at the very be-ginning, also named Ge (Zhou, 2006). The focus of this paper is on the development and use of Ge from the Shang Dynasty (c. 1600-1046 BC) to the period of the Warring States (475-221 BC), when combat vehicles were used.

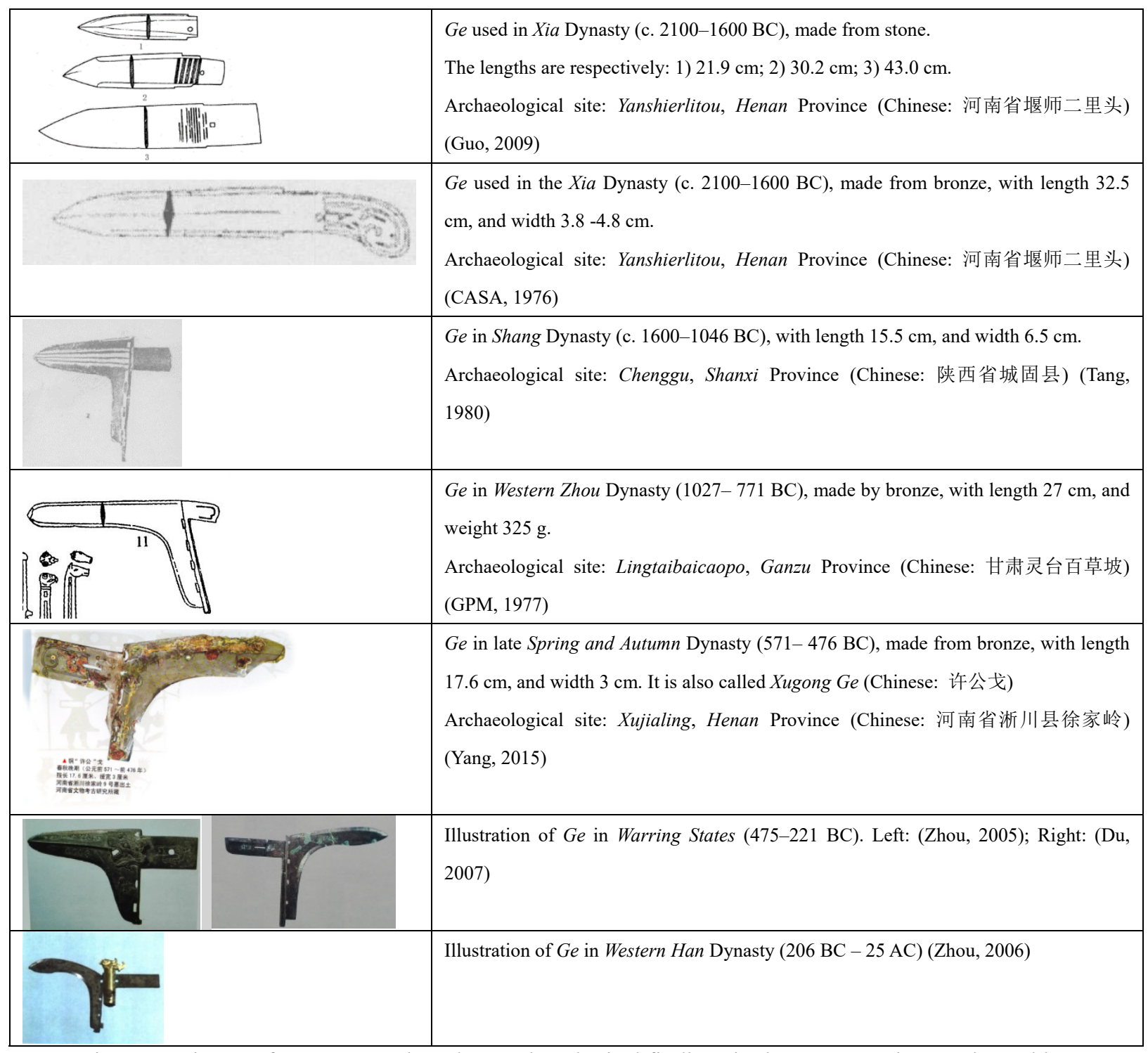

Figure 3. History of Weapon Ge, based on archaeological findings in the area covering Ancient China

The combat weapon Ge originated during the Shang Dynasty (ca. 1600-1046 BC). In the late Shang Dynasty (approximately ca. 1320-1046 BC), Ge was especially further developed to adapt to the emerging use of combat vehicles. The form of Ge was changing. Originally the sickle-shaped Hu was short. It developed to a much greater length until c. 1046 BC. Furthermore, the angle of Yuan (援) and sickle-shaped Hu changed from a right angle $90^{\circ}$ to an obtuse angle $\left(>90^{\circ}\right)$. In addition, the lower blade became curved. When the horse-drawn combat vehicles approached a group of the ene-mies, warriors (standing on the vehicles) used Ge to attack the enemies. This was somehow like cut-ting and harvesting with a sickle. In period of the Warring States (c. 475-221BC), with the use of cavalry, the use combat vehicles sharply decreased, and Ge was not used anymore. 
In view of several experts (Zhong, 1999; Yang, 1977; Shi \& Hu (Eds), 1996, Shen, 1992), the main reason that Ge developed and was widely used in Ancient China was the special use of the combat vehicles, especially from the late Shang Dynasty (c. 1320-1046BC) to the Western Han Dynasty (206 BC - 25 AC). In this period, combat vehicles were the main equipment of the army. Ground combats occurred frequently, and Ge became the main weapon for such combats.

When the horse-drawn combat vehicles approached enemies (the opposite side), the horses from both sides would not ride to each other and hit head-on, but would pass each other at a very short distance. Only in such very short time frame and on a relatively fast moving combat vehicle with high vibration, warriors on the combat vehicles could use weapons to attack each other. If other pole weapons would be used, such as battle axe, pike or lance, these could only be effective if they could target the fast-moving object very accurately in a small two-dimensional vertical range (height and width). However, on (fast) moving combat vehicles, it would be very difficult, if not impossible, to attack the moving target in a short time frame very accurately by using such pole weapons. With the weapon $\mathrm{Ge}$, if the warrior could point to the targeted objective at relatively accurate height range, within the operational range (length of reach) of Ge, the warrior could attack the enemy effectively. Using Ge does not only substantially increase the probability for the warrior to attack the target, but exploits the advantage of the kinetic energy of the (fast) moving combat vehicles to significantly increase the impact of the use of Ge. It can therefore be concluded that using Ge would be much easier, more practical and more effective than using any other weapon (available at that time) in such specific situation. Figure 4 illustrates the combat vehicle used in Ancient China when Ge was used.

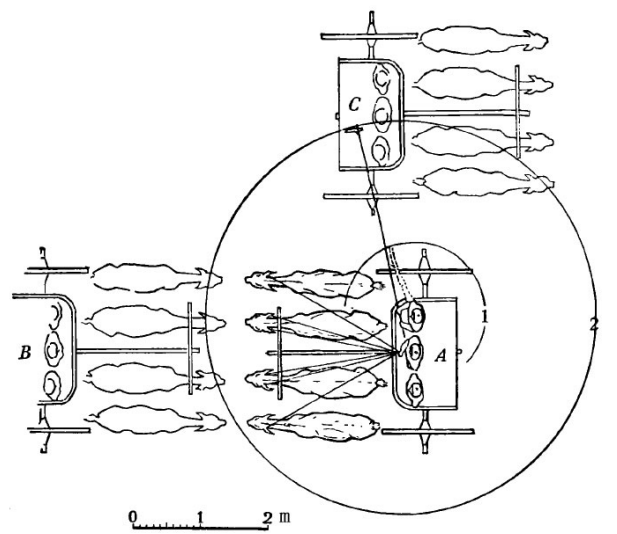

Illustration of the combat vehicles (horse-drawn), warriors, range of $G e$, and positions of combat vehicles $(A, B, C)$. A and $C$ are the fighting positions of the two combat vehicles.

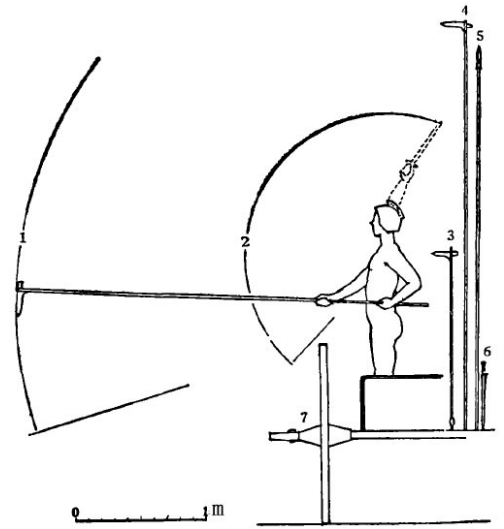

Illustration of attacking range of (1) Ge compared with the range of (2) sword, as well as a compilation of the lengths of weapons used on the combat vehicles: (3) short-range Ge, (4) long-range Ge, (5) spear, pike or lance, (6) sword.

Figure 4. Illustration of the use of combat vehicles and Ge in ancient warfare (adapted after Yang, 1977)

Combat vehicles, as important military equipment in the ancient world, have been widely used in other areas in the same period, e.g. by the Hittites, and in ancient Egypt and Assyria, including Mesopotamia that was conquered by Assyria (Jin, 2007).

There are two different views concerning the combat vehicles used in Ancient China. One considers that these were originally invented in Ancient China (Zheng, 1995); the other assumes that these were inspired by examples from other areas, including Middle East, spreading to Ancient China. The author supports the latter view, which is supported by archaeological evidence (Wang, 2001). When the technique of building combat vehicles entered Ancient China, the vehicles were further developed to adapt to the specific climatological and geographic situation (Guo, 2004).

Until now two issues still puzzle the researchers, for which no convincing solutions have been found.

1) In various regions and areas combat vehicles were also widely used in (large-scale) battles, such as in military campaigns in the Ancient Egypt of Thutmose III (1504-1450 BC), and in the Battle of Kadesh (or Qadesh) between the forces of the Egyptian Empire and the Hittite Empire at the city of Kadesh, (Shi, 1996; Healy, 1993). However, it was not found that such simple, pragmatic and highly effective weapon Ge was used in these area. In the rest of this paper we use the term "Middle East" to refer to the aforementioned areas (Hittites, ancient Egypt and Assyria). 
2) Weapons such as battle axe, spear, pike and lance also have their own specific powerful functions for cutting, cleaving, and thrusting. Although Ge has integrated functions, and delivers more lopping power against a moving target area (which also makes it more effec-tive for attacking warriors and horses protected by armours, due to concentrating more of its weight in the head), it is not for thrusting, and most capacities of Ge (if we look at these in isolation) are not better than those of the other pole weapons. However, Ge was widely used in a certain period in the battles of Ancient China, and the symbol was found in many Chi-nese characters (漢字) related to war and weapons. S. Zhong (1999) stated that only from a functional perspective, it is difficult to explain why in the Shang Dynasty (c. 1600-1100 BC) and the Zhou Dynasty (c. 1100-221 BC) Ge was used instead of battle axes, and this is still a puzzle.

\section{Ge - A Unique Weapon in Ancient Chinese History}

Based on in-depth study of historical and geographical data, as well as educated guess, we explore the reasons for the fact that Ge was only used in a certain period and only in certain areas. We start with comparative analysis of the structure of the "Middle-East Combat Vehicles" and the ones used in Ancient China, in terms of: (1) tactics (tactical grouping); (2) style of fighting, conducting opera-tions, warfare against enemies and battle; and (3) geographical, environmental and climatological conditions. Then we analyse other factors that may influence the creation and development of Ge.

\subsection{Comparative Analysis of the Structure of the Combat Vehicles in Mid East and Ancient China}

There are some similarities between the combat vehicles used in Middle East and Ancient China. For instance, both types of combat vehicles used wheels with spokes; the shape and the length of the hub (around the axle for fixing the spokes) in the two regions were very similar; there were hard-ly any differences in the shape, the components and the materials of the saddles, and the technique for making the combat vehicles were the same. (Wang, 2001) These observations indicate that the combat vehicles have the same source.

However, we notice some differences between the two, mainly reflected in the size. The combat ve-hicles used in Ancient China were much higher and stronger. They had larger wheels (or wheels with larger diameter) and a substantially larger number of spokes.

From literature and archaeological findings (see, e.g. (CASA, 1961)), in the Shang (商) Dynasty (c. 1600-1046 $\mathrm{BC}$ ), the wheel diameter was between $1.3 \mathrm{~m}$ and $1.5 \mathrm{~m}$, and the number of the spokes was mainly around 18 (although it was also found that some combat vehicles had 22, or even 26 spokes). During the Western Zhou period (西周) (c. 1046-771 BC), the horse-drawn combat vehicles were quite similar to those in the Shang (商) Dynasty, with minor developments, for instance: the wheel diameter was between $1.25 \mathrm{~m}$ and $1.45 \mathrm{~m}$, and the number of the spokes was between 18 and 28 (and most in the range 18-22). In the Spring and Autumn period (春秋) (770-476 $\mathrm{BC}$ ) the wheel diameter was between $1.25 \mathrm{~m}$ and $1.56 \mathrm{~m}$, and the number of spokes was normally 25 or 26 . During the Shang (商) Dynasty, the same vehicles were not only used for battles, but also for transport of people and goods (i.e. non-military use).

In the Spring and Autumn period (春秋), to adapt to the various needs and requirements, dependent on the types of battles, concerning combat vehicles (e.g. in terms of speed, manoeuvrability and toughness), vehicles were categorised according to different functions and the vehicles used for bat-tles were distinguished as "combat vehicles" for attack in combat, and "logistics vehicles" for transport of people and goods. The former needed higher speed and more flexibility, therefore, the wheel diameter was a bit smaller (mainly around $1.24 \mathrm{~m}$ ), while the latter had relatively larger wheels, with maximum of $1.7 \mathrm{~m}$ (Guo, 2004).

The combat vehicles use in the Middle East had small wheels, normally with less than one metre diameter. Before $1400 \mathrm{BC}$, in the Middle East the two-wheel vehicles powered by a horse often had wheels with 4 spokes. It was also found that before $2000 \mathrm{BC}$ the combat vehicle in the Hittite Em-pire had sometimes had wheels with only 8 spokes. After $1400 \mathrm{BC}$ the combat vehicle in Middle East had normally wheels with 6 spokes. Around $1000 \mathrm{BC}$ the combat vehicles found in the Hittite Empire and Persia had wheels with 7, 8 or 12 wheel spokes. The combat vehicles in Assyria and Per-sia, even after 700 BC, had wheels with not more than11-15. (加茂仪一, 1943)

Six well-preserved combat vehicles were found in 1922 in the tomb of the Egyptian pharaoh Tutan-khamun (who ruled ca. 1332-1323 BC according to the conventional chronology). The diameters of the wheels are $0.74-1.0 \mathrm{~m}$ and the number of spokes is 4-6 (Wang, 2001).

Different designs of the wheels are determined by specific functional requirements. These differ-ences will influence vehicle performance, such as usability for driving long distances in various ter-rain conditions, weight, load capacity and speed. From the comparative analysis of the wheels and the vehicle structure and materials, we found differences of focuses of the combat vehicles in differ-ent regions. The combat vehicles in Ancient China 
(which were high and strong, with a high chas-sis) target weighting capacity and driving long distance in various terrain conditions; the combat vehicles in the Middle East (which were small, light and flexible with low chassis) target speed and manoeuvrability. The combat vehicles in Ancient China are heavier than those in the Middle East also due to use of different materials: in the Middle East, the main framework of the vehicles was made from wood, and the side and bottom parts were made from feather or ropes; in Ancient China, nearly all parts of the combat vehicle were made from wood.

\subsection{Comparative Analysis of Tactical Grouping and Battle Style in the Middle East and Ancient China}

The combat vehicles in the Middle East were light, for high speed and good manoeuvrability. The combat vehicles used during period of the Egyptian pharaoh Tutankhamun, weighed only $35 \mathrm{~kg}$. The vehicle performance was tested by using a reproduced vehicle drawn by two ponies. It was found that it could reach a speed of $38 \mathrm{~km} / \mathrm{h}$, and that it could travel a distance of 50-60 km per day (Anglim \& Jestice, 2003). During a battle, such chariot could use its advantage of high speed, quickly move to a proper position in a battle field; the warriors could use bow and arrows to attack the ene-mies from a certain distance and could quickly escape (if they could not defeat the enemy). There were hardly any combats at very short range in the ancient Middle East. Therefore, a military force was grouped by combat vehicle and infantry units. These two types of tactical troops operated inde-pendently. (Shi \& $\mathrm{Hu}$ (Eds). 1996)

The combat vehicles in Ancient China, compared with those in the Middle East, were heavier (due to the fact that all components were made from wood), with larger wheels. Consequently, there were disadvantages in terms of speed and manoeuvrability. Due to lower speed, the combat vehicles could not quickly escape when they were attacked by an infantry. Therefore, the combat vehicles would need protection and support from an associated infantry unit. Consequently, a combat vehicles unit and and infantry unit were components of one troop, and the two units fought in coordination, which was the basic model of the military force in Ancient China (Shi \& Hu (Eds). 1996). Apparent-ly the combat vehicle speed was low enough for the infantry to follow and provide support. It should also be emphasised that the ancient combat vehicle did not use tyres (Wang, 2001).

In the same period, in other parts of the world, combat vehicles were using wheels with tyres made from leather to reduce the vibration of the moving vehicles with high speed (Wang, 2001). This dif-ference (of the use of tyre) explicitly proofs that the combat vehicles used in Ancient China were of lower speed, because of which there was no need to reduce variation. Wang (2001) also provides evi-dence that wars, and large-scale wars with the involvement of combat vehicle,s happened more fre-quently during the Spring and Autumn period (Chinese: 春 秋), (770-476 BC): 483 battles, including 376 large-scale combats, are reported in Zuo Zhuan (Chinese: 左傳; "Zuo Tradition" or "Commen-tary of Zuo" - an ancient Chinese narrative history that is traditionally regarded as a commentary on the ancient Chinese chronicle Spring and Autumn Annals). The basic unit of a military force was called Cheng (Chinese: 乘). A Cheng is composed of one combat vehicle powered by four horses, three warriors (on the vehicle), and seventy-two infantry (Shi \& Hu (Eds). 1996). In general, the warriors were from the nobility, while the infantrymen came from lower social classes. In Chinese, Cheng was also used to describe the size and scale of a military force, e.g. thousands of Cheng and ten thousands of Cheng. When the battle started, a general model was that 1) the combat vehicles, accompanied by infantry, drove to the enemy; 2) when the opposite sides closed to each other ade-quately, they first used bow and arrow to attack each other; 3) and then the combat vehicles drove towards each other and warriors on the vehicles fought face-to-face with polearms. (Chen, 1991)

From this comparative analysis, we find that: during the wars in the Middle East, mainly bows and arrows were used (from the fast moving combat vehicles), and there were hardly fights between combat vehicles at a very short distance; in Ancient China, besides using bows and arrows, fights were at a very short distance on the moving vehicles. In such situation, the pole weapon Ge would be much more effective for attacking the enemy) than any other weapon, such as battle axe, spear, pike and lance. Therefore, Ge became part of the standard components of the use of combat vehi-cles, and the most important weapon for the combat with horses-drawn vehicles.

From the abovementioned analysis, the first puzzle concerning the reasons of the use of Ge in An-cient China is solved. However, in that period, both in Ancient China and in the Middle East, the technique for making combat vehicles was mature, and every country in the Middle East could also make large vehicles as in Ancient China; and small combat vehicles could also be made in Ancient China as in the Middle East; but why did this not happen, why did the two regions make a different choice.

\subsection{Comparative Analysis of Geography and Climate in the Middle East and Ancient China}

Most areas in the Middle East belong to tropical and subtropical zones, which are often influenced by high (atmospheric) pressure at the Tropic of Cancer and trade-wind zones. The climate is dry and hot, with arid or sub-arid zones. 
Mesopotamia (in the Middle East), had an extremely moistures period approximately before $4000 \mathrm{BC}$. Around $3500 \mathrm{BC}$, the climate in this area became dry. Due to this sharp change, the marsh-lands in the area of Babylonia (which was situated at the southern part of the Tigris-Euphrates river system) gradually dried, and the land became rich and fertile. In the same period, the climate in Af-rica saw a substantial change: the oases in the Sahara desert gradually disappeared, lakes dried, dunes developed and the desert appeared and extended. Ancient people, who lived next to oases and lakes had to leave their homes and migrated to the Nile River valley and the Nile Delta zone. With the increase of population density, tribes were generated, countries were established, and conflicts be-tween countries also occurred frequently.

In Mesopotamia, the northern mountainous area belonged to the Mediterranean Climate, while oth-er areas were in the sub-tropical zone, with arid and sub- arid climate. Due to scarce and very limited rainfall (by nature), agriculture in the area depended on artificial irrigation. At the very early stage, various irrigation systems in this area were built. For instance, an important large-scale public activi-ty in Mesopotamia was to build canals. Many data indicate that (Song \& Li, 2014; Nemet-Nejat, 2002) in the old Babylon period, each King took irrigation as most important, and took the activities of building canals as important merits and virtues, and as contributions to society giving immoertal status (Song \& $\mathrm{Li}, 2014$ ).

Ancient Egypt, which was another area in the Middle East, situated in the Nile River basin, which was very dry and hot, with hardly any rain. The Nile River Delta and the northern part of the area along the coast were in the subtropical Mediterranean climate zone, which had a relatively temper-ate climate, compared with other areas at the same latitude. However, the major of ancient Egypt (outside the Nilke valley and delta area) had an arid tropical desert climate. Due to scarce rainfall, vegetation in this area had (semi-)desterilised characteristics. Cultivation was centralised in the areas of the Nile River basin and the Delta plain (or flatland) along the coast, and the irrigation mainly depended on the periodic flooding of Nile River.

From this geographic and climate information, one can conclude that in the region of the ancient Middle East (due to arid climate with scarce rainfall) the moisture content of the soil was very low, and that therefore the soil was rather hard. Except in agriculture fields (through artificial irrigation), vegetation in most fields was sparse. Therefore, there were hardly any obstacles in the fields for moving vehicles. Such geographic environment is suitable for driving combat vehicles at high speed. Therefore, it is very reasonable that small wheel combat vehicles were used in The Middle East, with the advantages of speed and manoeuvrability.

The geography and climate in Ancient China, before the Qin Dynasty, were completely different from the Middle East. According to K. Zhu (1972), the climate in the Yellow River basin had only a short cold period in the early Western Zhou period, and most of the time it was rather warm, even warmer than at present in the same area. It was indicated that the northern boundary of the distribu-tion of bamboo in Ancient China moved approximately 3 degree latitude to the north compared with the current situation. Animals, such as elephant, rhinoceros, river deer and water buffalo, that we can currently only find in tropics and subtropics, appeared in Ancient China (Zhang, 2007). In An-cient China, the climate of the Yellow River area was similar like the current climate of the Yangzi River (Zhu, 1972), and the irrigation system mainly depended on rainfall (Wang, 2001).

A lot of oracle inscriptions (on tortoiseshells or animal bones) about praying for rain were found, including from the oracle bone script (Chinese: 甲骨文) in the Shang Dynasty (c. 1600-1046 BC) (Guo (Ed.), 1982; Dong, 1948; Liu \& Huai, 1954; Fan, 1965; Guo, 2012). Rainfall had a big impact on agriculture in Ancient China. The reason is that most areas belonged to a continental monsoon climate, and the main source of rainfall was the monsoon in the summer. In that period of Ancient China, it was hot and rainy in the summer, and the weather in the autumn was very comfortable (no rain and with moderate temperature).

Such weather and climate were very good for agriculture in Ancient China. Therefore, artificial irri-gation was not needed in that period, and started much later compared with the Middle East (Wang, 2010). Except in the Chinese myth about Yu the Great (Chinese: 大禹), a legendary monarch of the Xia Dynasty (c. 2070-1600 BC), who became famous for his introduction of flood control, recorded in the Records of the Grand Historian (Chinese: 太 史公書 or 史記) Sima Qian (Chinese: 司馬遷), finished around 94 BC, no convincing evidence of large-scale irrigation projects before the Warring States period (Chinese: 战国) (475-221 BC) was found.

Furthermore, concerning the geographic environment before the Qing Dynasty, in the middle and lower reaches of the Yellow River, there were not only a lot of rivers, but also many lakes and marshes. Zou (1987), based on the literature Zuo Zhuan (Chinese: 左傳) and the Classic of Moun-tains and Seas (Chinese: 山海经; around the 4th century BC), counted in this period 24 lakes and marshes in the current Henan Province, and inferred that there were many more lakes and marshes in the ancient plain of the Yellow River and Huai River (Chinese: 淮河; located about mid-way be-tween the Yellow River and Yangtze). 
Yang and Ma (2010) described the number of lakes and marshes as the stars in the sky. In addition, from the oracle inscriptions, it was found that according to the hunting statistics in the Shang Dyn-asty, elk was the most captured animal, and the record was more than 700 during one hunt activity. As elks live close to water, it also proved the special geographic environment in that period.

We can conclude that the area of the Huang River in Ancient China was surrounded by mountains and hills, covered by forest and grasses, and that lakes and marshes were widely scattered. Due to high rainfall, the moisture content of the soil was high, and vegetation in this area grew thick. In this circumstance, combat vehicles were confronted with many obstacles (such as marsh-land, swamp and shrubbery) which made it difficult to move.

From the literature of the proto-writing on bronze equipment founded in Western Zhou (Chinese: 西周) (1046-771 BC) (Ge \& Wei, 2014), the following was found: be careful and do not let our army fall in the swamp (Chinese: 弗 与我车南于艰). In Zuo Zhuan, it was also reported that in 575 BC, during the War of Yan Lin (Chinese: 鄢陵), which is located in the middle of the current Henan Province, when the military force of Jin (Chinese: 晋) was trying to attack the military force of Chu (Chinese: 楚), it was confronted with a swamp. The infantry unit of the military force (that was in the front) completely fell in the swamp; and the combat vehicle unit had to take a detour. Due to the obstacles of the swamp, the military force of Jin nearly lost the battle (Lan 1979). From the aforementioned examples, it is clear that the main issue for combat vehicles in Ancient China was adaptation to the ground conditions and improvement of the capability for long distance driving (horse-drawn). Obviously, small wheel vehicles (as widely used in the Middle East) were not suitable for such circumstances. This makes it understandable that the combat vehicles in Ancient China had larger wheels with more spokes and a higher chassis.

\subsection{Analysis of Other Factors that may Influence the Creation and Development of Ge}

In the previous sections, we have proposed convincing arguments why the weapon Ge was not used outside Ancient China, and only used in the certain period (based on archaeological findings, and historical and geographical studies). Another factor, which is worthwhile to be addressed, is the de-velopment of the horses and the cavalry. Between the Shang Dynasty and the Western Han period, the development of cavalry was not mature. Wild horses were just tamed and trained for domestic use, e.g. for carrying goods. But these were still not strong enough for riding or carrying cavalry-man. Horses were mainly used in the war to transport combat vehicles with warriors and $\mathrm{Ge}$, and the carriages were also used as a powerful mobile platform for the warriors to fight with $\mathrm{Ge}$ at a short distance, either warriors (standing on the combat vehicles) against other warriors, and warriors against infantrymen (on foot). Gradually, the tamed horses became stronger and were able to carry cavalrymen. With the development of cavalry becoming mature and the development of the cross-bow (in the Warring States period), combat vehicles did not play an important role any more, and gradually the combat vehicles were replaced by cavalry. With a crossbow (big and slowly moving) combat vehicles could be shot from a long distance. Therefore, combat vehicles became unpractical and useless, and disappeared during the Eastern Han period (25-220 AD). Consequently, the use of weapon Ge also came to an end.

\section{Impacts of the Weapon Ge on Military and Culture}

As an important weapon in history, Ge was invented, developed, and widely and intensively used, especially before the Qin Dynasty. At a later stage, various versions of the weapon Ji (Chinese: 戟) were developed based on $\mathrm{Ge}$. It combines a head of spear with one or more heads of Ge on a pole (Zhong, 1999).

During the period in which Ge was booming, the civilisation of Ancient China developed. Oracle bone script (Chinese: 甲骨文) developed during the Shang Dynasty, Chinese bronze inscriptions (Chinese: 金文, 銘文, or 钟鼎文) developed during the Western Zhou period, and seal script (Chi-nese: 䇡書), used between the Warring States period and the Qin Dynasty, was standardised during the Qin Dynasty and is still used at present as part of the Chinese character system (Chinese: 漢字). Chinese characters were in general developed and used by the upper-class. Before 221 BC (i.e. before the Qin Dynasty), Ancient China was composed of kingdoms and city-states. The system is similar as in the period of the Delian League in Ancient Greece. However, the difference is that in Ancient China, one of the city-states was a centralised government. In that period, nobility and lower social class public were from the same tribe. Both of them served the army and attended the war. Noble warriors were the main users of Ge. Therefore, Ge was considered as a noble weapon. Consequently, it was used in the characters by noble people.

We can notice that (which is a shape of combat axe) was used as a component of Chinese char-acters. And later this was re-shaped to (which is a shape of Ge), an used often as a radical of Chinese characters that are related to military terms, such as war, fighting, weapon, arm, punish-ment. The Kangxi Dictionary lists 116 characters (out of 49,030 ) under this radical. In the current set of Chinese characters some with the radical Ge are still in use, e.g.

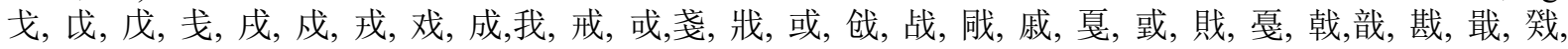




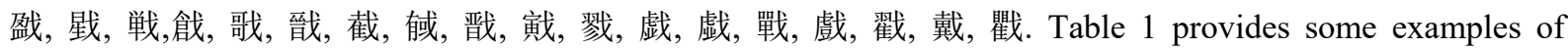
Chinese characters with Ge as radical in Oracle bone script, Chinese bronze inscriptions, and seal script, and illustrates how the characters were developed. The Chinese character "戈" has also been widely used in ancient essays and poems, as well as in more than 80 Chinese idioms (see Table 2)

Table 1. Examples of Chinese characters with radical Ge (Chinese Dictionary Ed. Group, 1993)

\begin{tabular}{|c|c|c|c|c|c|c|}
\hline No. & Name & $\begin{array}{l}\text { Description } \\
\text { (Current vs. Original) }\end{array}$ & $\begin{array}{l}\text { Current } \\
\text { character }\end{array}$ & $\begin{array}{l}\text { Oracle bone } \\
\text { script }\end{array}$ & $\begin{array}{l}\text { Chinese Bronze } \\
\text { inscriptions }\end{array}$ & $\begin{array}{l}\text { Seal } \\
\text { script }\end{array}$ \\
\hline 1 & $w u$ & $\begin{array}{l}\text { Current: military; valiant; fierce } \\
\text { Original: to march with } G e\end{array}$ & 武 & $\frac{f}{y^{*}}$ & 点 & 芯 \\
\hline 2 & zhan & $\begin{array}{l}\text { Current: fight } \\
\text { Original: to fight with } G e \text { and bow }\end{array}$ & 战 & - & 單 & 哭 \\
\hline 3 & $l u$ & $\begin{array}{l}\text { Current: kill; slays } \\
\text { Original: to cut the head of a tribe leader }\end{array}$ & 戮 & - & 䎑 & 翏 \\
\hline 4 & $f a$ & $\begin{array}{l}\text { Current: attack; cut down; strike } \\
\text { Original: to cut the head with } G e\end{array}$ & 伐 & 析 & 礼 & 腍 \\
\hline 5 & $J i$ & $\begin{array}{l}\text { Current: an ancient weapon based on Ge } \\
\text { Original: weapon used by army }\end{array}$ & 戟 & - & 较 & 等 \\
\hline 6 & qiang & $\begin{array}{l}\text { Current: injure; harm; undermine } \\
\text { Original: to kill when one is in bed }\end{array}$ & 战 & 3 & 类 & 䄾 \\
\hline 7 & $g e$ & $\begin{array}{l}\text { Current: a weapon } \\
\text { Original: a polearm with blade and } H u\end{array}$ & 戈 & 5 & $\frac{f}{x}$ & $\frac{n}{x}$ \\
\hline 8 & rong & $\begin{array}{l}\text { Current: army; military affairs } \\
\text { Original: Ge and shield, i.e. basic equipment of } \\
\text { ancient solders }\end{array}$ & 戎 & $\bar{F}$ & 槙 & 或 \\
\hline 9 & shu & $\begin{array}{l}\text { Current: defend; garrison } \\
\text { Original: a military guard with Ge on his shoulder }\end{array}$ & 戌 & 1 & 资 & $\frac{n}{r}$ \\
\hline 10 & jie & $\begin{array}{l}\text { Current: guard against; warn; stop } \\
\text { Original: to hold } G e \text { in two hands, i.e. alert and } \\
\text { read to fight }\end{array}$ & 戒 & & 秦 & E \\
\hline 11 & $w u$ & $\begin{array}{l}\text { Current: the fifth of the ten Heavenly Stems } \\
\text { Original: to fix an axe head on } G e\end{array}$ & 戊 & $H$ & ft & $\sqrt{x}$ \\
\hline 12 & $x u$ & $\begin{array}{l}\text { Current: the } 11 \text { th of the } 12 \text { th Earthly Branches } \\
\text { Original: combat axe, which is bigger than } w u \text { 戊 }\end{array}$ & 戌 & $G$ & 位 & 展 \\
\hline 13 & $q i$ & $\begin{array}{l}\text { Current: a Ge-like weapon in ancient China; } \\
\text { sorrow; relative } \\
\text { Original: combat axe with two-side sharp teeth }\end{array}$ & 戚 & 些 & 旗 & 藏 \\
\hline 14 & $z a i$ & $\begin{array}{l}\text { Current: (used in exclamations) } \\
\text { Original: war disaster (fire + military) }\end{array}$ & 哉 & 卉 & 裁 & 传 \\
\hline
\end{tabular}




\section{Discussion}

We have compared the use of combat vehicles in Ancient China and the Middle East. In Homer's Iliad, we can find descriptions of Greek combat vehicles (called chariots), which were used for racing, and for transporting warriors to a battle. The main reasons that these combat vehicles were dif-ferent from the ones used in ancient China are: (1) the topography in ancient Greece was completely different; and (2) development of cavalry. Ancient Greece was composed of small plains, hills and mountains. It was not suitable for combat vehicles, as these could only be functional when used in a large flat area without or with limited obstacles. Ancient Greece had a long history to use infantry-men. The number of cavalry and vehicles used in military forces were not large. In addition, when city-states were established in Ancient Greek, cavalry was already mature. A similar situation was also applicable in ancient Rome. Therefore, there was no need to have a combat vehicle unit. (Shi \& Hu (Eds), 1996)

Concerning the development of the materials for ancient weapons, Ge was first made from stone, from the Stone Age to Xia Dynasty (c. 2070-1600 BC) (Zhong, 1999). During the Shang Dynasty (c. 1600-1046 BC), the main weapons were Ge, spear, pike, lance, battle axe, sword, bow and arrow. The main material used in this period was bronze. In this period, large amounts of bronze weapons were produced and used. However, it took a long time for bronze to completely replace stone and other materials, e.g. horns of animals. In the end of the Shang Dynasty (approximately 1320-1046 BC), although the bronze weapons were mainly used, the heads of the arrows were still made from stone or horns of animals (Wang, 2001; Lu, 1999).

In the late part of the Western Zhou period, iron weapons developed. In the Eastern Han period, bronze weapons were not used any more and completely replaced by iron weapons. During the War-ring States period (475-227 $\mathrm{BC}$ ), then crossbow was invented. Meanwhile, due to the improvement of metallurgical technology, iron weapons were widely used, such as polearms, and the iron sword. Combat vehicles were less used. Meanwhile, infantry and cavalry became the main forces. The weapons, such as spear and knife (used by infantrymen and cavalrymen) became the important equipment of a military force. (Zhong, 1999; Wei, 2011; Lu, 1999)

The use of different materials for the weapon Ge in Ancient China is summarised in Figure 5. Note that the periods in Chinese chronology are often defined with different years in different literature.

\begin{tabular}{|c|c|c|c|c|c|c|c|}
\hline \multirow{2}{*}{$\begin{array}{c}\text { Xia } \\
\text { Dynasty } \\
\text { (c. } 2100- \\
1600 \text { BC) }\end{array}$} & \multirow{2}{*}{$\begin{array}{c}\text { Shang } \\
\text { Dynasty } \\
\text { (c. 1600- } \\
1046 \text { BC) }\end{array}$} & \multirow{2}{*}{$\begin{array}{l}\text { Western } \\
\text { Zhou }\end{array}$} & \multicolumn{2}{|c|}{ Eastern Zhou Dynasty } & \multirow{2}{*}{$\begin{array}{c}\text { Qin } \\
\text { Dynasty } \\
(221-206 \\
\text { BC) }\end{array}$} & $\begin{array}{c}\text { Western } \\
\text { Han }\end{array}$ & $\begin{array}{c}\text { Eastern } \\
\text { Han }\end{array}$ \\
\hline & & & $\begin{array}{l}\text { Spring and } \\
\text { Autumn }\end{array}$ & $\begin{array}{c}\text { Warring } \\
\text { State }\end{array}$ & & \multicolumn{2}{|c|}{$\begin{array}{c}\text { Han Dynasty } \\
(206 \mathrm{BC}-220 \mathrm{AD})\end{array}$} \\
\hline
\end{tabular}

\begin{tabular}{|c|c|c|}
\hline \multirow{2}{*}{$\begin{array}{l}\text { Stone and Bronze } \\
\text { (before Xia Dynasty, } \\
\text { c. } 4700-2070 \mathrm{BC} \text { ) } \\
\end{array}$} & \multirow{2}{*}{$\begin{array}{c}\text { Bronze } \\
\text { (Xia Dynasty } \sim \text { Spring and Autumn } \\
\text { c. } 2100-256 \text { BC) }\end{array}$} & $\begin{array}{c}\text { Iron } \\
\text { (as of Warring State) }\end{array}$ \\
\hline & & \multirow{2}{*}{$\begin{array}{c}\text { Bronze and Iron } \\
\text { (Warring State } \sim \text { Western Han } \\
\text { c. } 475 \mathrm{BC}-214 \mathrm{AC})\end{array}$} \\
\hline & & \\
\hline
\end{tabular}

Figure 5. Illustration of materials development in Ancient China (from the Stone Age to the Bronze Age and the Iron Age) when the weapon Ge was used

\section{Conclusions}

Ge was a unique weapon invented before the Qin Dynasty in ancient China (also called "Middle Kingom"), with a (horizontal) double-bladed and a sickle-shaped Hu. Ge was spe-cifically designed for combat, and could cleave, cut, shape, split, and lasso-liked weapon (designed as a restraint to be slung around a target, to hit and pull). It also becomes a cere-monial or heraldic symbol. (Zhong, 1999). 
The weapon Ge was used before the Qing Dynasty, and popular between the Shang Dynasty and the Western Han period in Ancient China (Ye, 2013). This unique weapon was only used in ancient China in a certain period, when combat vehicles were widely used. Specific geo-graphic environmental and climatological circumstances influenced the design and use of the military equipment (including the performance of the combat vehicles). The special tac-tical grouping, battle style and combat vehicles used in ancient China were essential inte-grated factors of the invention of $\mathrm{Ge}$, which had many advantages, and was more powerful and effective than other weapons for the battles in that specific period. See Figure 6.

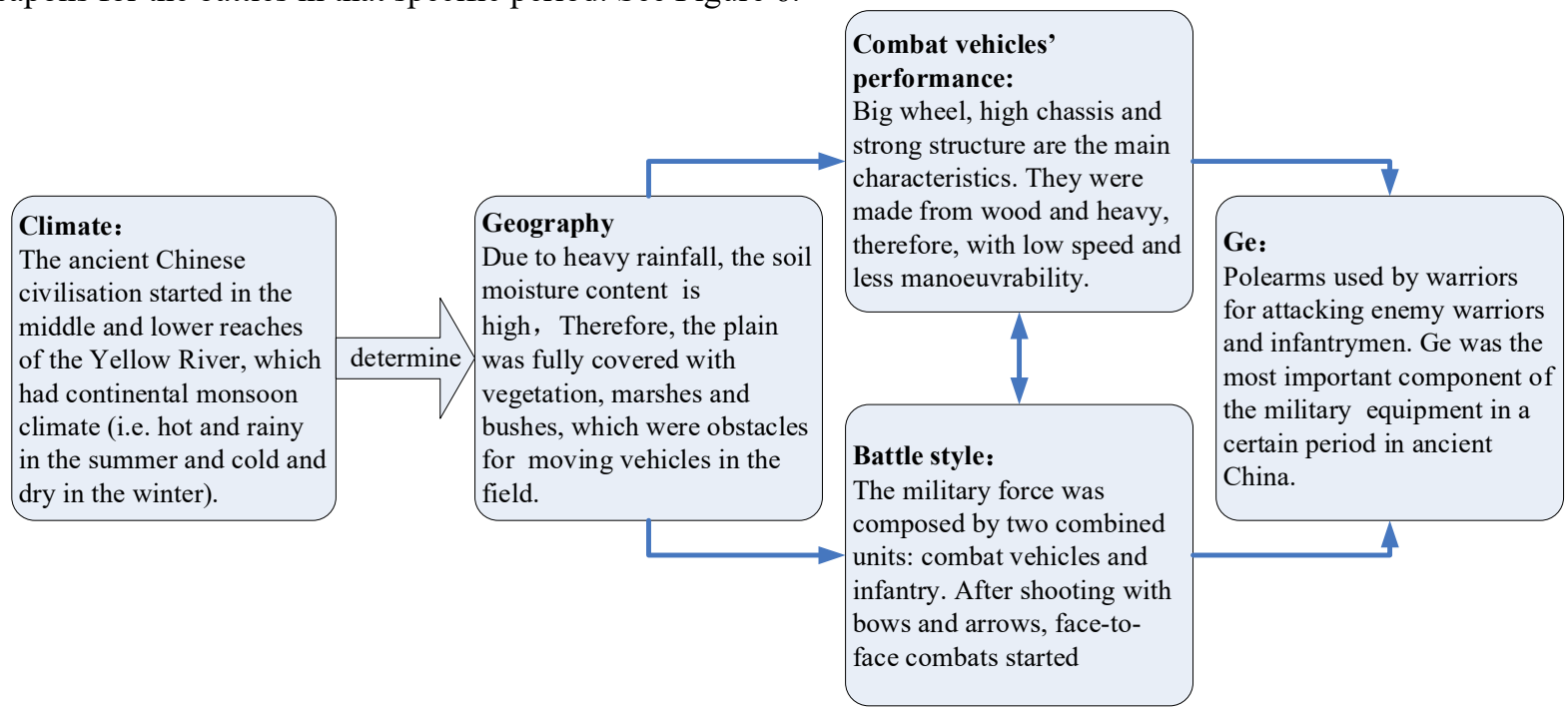

Figure 6. Summary of the generation of weapon Ge

Ge had substantial impacts on Chinese culture. "戈" (Ge) was used in Chinese character (漢字) (also as part of the structural component of other Chinese characters, called radical), id-ioms, essays and poems. It also contributed to the development of a new weapon in the mili-tary history.

\section{Acknowledgments}

The paper presents recent results of the project on Military History, Geography and Culture, funded by Heilongjiang University, P.R. China. The author especially thanks his colleagues for their support, as well as Kees Wevers (The Netherlands) and Dr. Meng Lu (The Netherlands) for their contributions to the preparation of the manuscript.

\section{References}

Anglim, S., \& Jestice, P. (2003). Fighting Techniques of the Ancient World (3000 B.C. to 500 A.D.): Equipment, Combat Skills, and Tactics. St. Martin's Press, New York.

CASA (Chinese Academy of Sciences, Institute of Archaeology). (1961). Archaeological findings of P.R. China. Beijing: Antique Press. (in Chinese)

CASA (Chinese Academy of Sciences, Institute of Archaeology) Erlitou Working Group. (1976). Bronze and jade made equipment found at Archaeological site Yanshierlitou. Archaeology, 4, 260. (in Chinese)

Chen, E. (1991). Studies on the military ideology before Qin Dynasty. Changchun: Jilin Culture \& History Press.

Chinese Characters Dictionary Ed. Group. (1993). Chinese Dictionary. Chengdu: Sichuan Dictionary Press. (in Chinese)

Dong, Z. (1948). Characters used in Shang Dynasty (2nd ed.). Part I. Chinese Research Centre, Institute of Language and History. Beijing. (in Chinese)

Du, W. (2007). Clarifications of Chinese ancient weapons and books via pictures. Beijing: World Book Press Inc. (in Chinese)

Fan, Y. (1965). After Han Dynasty. Beijing: Chinese Press. (in Chinese)

Ge, H., \& Wei, S. (2014). Studies on Gui (Chinese: 篮; it is a type of bowl-shaped ancient Chinese ritual bronze vessel widely used between Shang Dynasty and Eastern Zhou). Assessment and Enjoyment of Antique, 1, 90-93. 
GPM (Gansu Province Museum, Antique Group). (1977). Western Zhou Comb in Lingtaibaicaopo, Ganzu Province. The Journal of Archaeology, 2, 99-147. (in Chinese)

Guo, M. (1982). Reports on Oracle Bone Script. Chinese Academy of Social Sciences, Institute of History. Beijing: Chinese Press. (in Chinese)

Guo, W. (2004). Essential Issues - Chinese ancient combat vehicles and horses. Chengdu: Sichuan People's Press. (in Chinese)

Guo, Y. (2009). Study of the ancient weapons found in Erlitou. Jinag Han Archaeology, 3, 69-71. (in Chinese)

Guo, H. (2012). Archaeological findings of official activities of praying for rainfall. The Journal of Guang-xi University (Series: Philosophy and Social Science), 1, 70-77.

Healy, M. (1993). Qadesh 1300 B.C, Clash of the Warrior Kings. Osprey Publishing; Osprey Campaign Series $\# 22$.

Lan, Y. (1979). The infantry unit of the military force in Spring and Autumn Dynasty. Beijing: Chinese Press. (in Chinese)

Li, J. (1932). Studies of the five bronze weapons of Shang Dynasty and related issues. Beijing: Archaeology. (in Chinese)

Liu, A., \& Huai, N. (1954). Series of studies of countries. Beijing: Chinese Press. (in Chinese)

Lu, J. (1993). History of Chinese ancient weapons. Xi'an: Xi'an Jiaotong University Press. (in Chinese)

Lu, D. (1999). Historic periods of using both stone and bronze, and using bronze only. The Journal of Xi'an University of Architecture and Technology (Series: Social Science), 1, 47-51. (in Chinese)

Morgan, J. J. de. (1921). L'humanité préhistorique, esquisse de préhistoire générale. Re-naissance du Livre, Paris. (in French)

Nemet-Nejat, K. R. (2002). Daily life in Ancient Mesopotamia. Massachusetts: Hendrickson Publishers Inc..

Shen, R. (1992). Study on the use of Ge made by bronze. Archaeology, 1, 69-75. (in Chinese)

Shi, Z., \& Hu, X. (Eds.) (1996). History of military in the world. Beijing: International Broadcasting Press of P.R. China. (in Chinese)

Song, J., \& Li, H. (2014). Irrigation systems for agriculture in Ancient Babylon. Agriculture Archaeology, 6, 278-281. (in Chinese)

Tang, J. (1980). Report on bronze of Shang Dynasty found in Chenggu, Shaxi Province. Archaeology, 3, 213. (in Chinese)

Yang, H. (1977). A series of Chinese ancient military equipment - combat vehicles and their use in wars. Historical Relic, 5. (in Chinese)

Yang, N., \& Ma, J. (2010). Economy, science and technology in Shang Dynasty. Beijing: Chinese Social Science Press. (in Chinese)

Yang, P. (2015). Assessment and enjoyment of Chinese ancient weapons. History of Military, 4, 66-67. (in Chinese)

Ye, S. (2013). Source of the culture of Ge and creation of the civilisation of Ancient China. Ethnic Nations Art, 1, 24-31. (in Chinese)

Yin, Y. (2007). Studies on ancient combat vehicles. Military History, 2, 113-118. (in Chinese)

Wang, H. (2001). Generation of the vehicles powered by horses in China. Asian and European Studies, 0, 1-75.

Wang, S. (2010). Chinese ancient water management facilities and characteristics. The Journal of Shanxi Normal University (Series: Philosophy and Social Science), 2, 109-117.

Wei, B. (2011). Dictionary of Chinese weapons and body armours. Beijing: Chinese Press. (in Chinese)

Zheng, R. (1995). Sources of the ancient vehicles powered by horses in China. Chinese Archaeology, 3, 41-56. (in Chinese) DOI: 10.16143/j.cnki.1001-9928.1995.03.003

Zhong, S. (1999). Weapons Ge and Ji - History and culture of Chinese ancient weapons. Beijing: Chinese People's Liberation Army (PLA) Press. (in Chinese)

Zhou, W. (2006). History of Chinese weapons. Tianjin: Baihua Culture \& Art Press. (in Chinese) 
Zhu, K. (1972). Studies on climate changes in recent 5000 years in China. The Journal Archaeology, 1, 15-38. (in Chinese)

Zou, Y. (1987). Historical changes of lakes and marshes in Huabei Area. Historical Geography. Shanghai: Shanghai People's Press.

加茂儀一. (1943). 家畜文化史 改造社 1937 年 世界文化史 三笠書房 1938 年 (三笠全書) 技術発達史 商工行政社 1943 年 (技術文化大系) ルネサンスとヒューマニズム. (in Japanese)

\section{Copyrights}

Copyright for this article is retained by the author(s), with first publication rights granted to the journal.

This is an open-access article distributed under the terms and conditions of the Creative Commons Attribution license (http://creativecommons.org/licenses/by/3.0/). 